\title{
Nature of Zirconium Phosphite as an Acidic Catalyst
}

\author{
Ben-Zu Wan* and Soofin Cheng \\ Department of Chemical Engineering and Department of Chemistry, National Taiwan University, \\ Taipei, Taiwan, Republic of China \\ Rayford G. Anthony and Abraham Clearfield \\ Department of Chemical Engineering and Department of Chemistry, Texas A\&M University, College \\ Station, TX 77843, USA
}

\begin{abstract}
The nature of acidic sites on layered zirconium phosphite has been characterized by IR spectra, thermal analysis and catalytic dehydration of ethanol. The catalytic behaviour was compared with that of $\alpha$-zirconium phosphate. The reaction sequences for ether and ethene formation were studied by analysing the kinetic data. The Brønsted acidity of monohydrogen orthophosphate groups was considered to be the common active site on $\alpha$-zirconium phosphate and the zirconium phosphite sample calcined at $673 \mathrm{~K}$. For the latter compound, the phosphite groups on the exterior surface were found to be oxidised to phosphate by calcination in air. The uncalcined sample of zirconium phosphite exhibited a different catalytic behaviour. Its selectivity for diethyl ether was the highest among the catalysts studied. The dehydration activity of this compound was presumed to be due to the polar $\mathrm{P}-\mathrm{H}$ bonds in the phosphite groups.
\end{abstract}

Crystalline zirconium phosphite and zirconium phosphate have similar layered structures. ${ }^{1-3}$ In crystalline $\alpha$-zirconium phosphate, $\mathrm{Zr}\left(\mathrm{HPO}_{4}\right)_{2} \cdot \mathrm{H}_{2} \mathrm{O}$, the zirconium atoms lie almost in a plane and are bridged by phosphate groups situated alternatively above and below the plane. ${ }^{3}$ Each orthophosphate group has three oxygen atoms bonded to three different zirconium atoms, while the fourth oxygen atom bears a proton and behaves as a Brønsted-acid site. This $\mathrm{P}-\mathrm{OH}$ group has demonstrated interesting catalytic properties in the dehydration of alcohols ${ }^{4,5}$ and isomerization of butene. $^{6}$ Although the interlayer distance of $\alpha$-zirconium phosphate is $c a$. 7.6 $\AA$, the free space between the layers is only $2.6 \AA$, which is too small to accommodate any organic molecules. Therefore, only the exterior surface of zirconium phosphate particles is responsible for the catalytic activity. Recently, it was shown that pillared derivatives of $\alpha$ zirconium phosphate could be prepared in the form of organically pillared phosphates and phosphonates. ${ }^{7}$ By spacing the phosphate groups with phenyl or biphenyl groups, porous structures were created and the interior surface was explored for catalytic reactions. ${ }^{5,8}$

By analogy with the $\alpha$-zirconium phosphate structure we may consider that in the structure of zirconium phosphite, each phosphite group uses its three oxygen atoms to bridge bond with the zirconium atoms, and leaves a free $\mathrm{P}-\mathrm{H}$ group pointing away from the basal planes. Because the $\mathbf{P}-\mathbf{H}$ bond is partially covalent, it is expected that zirconium phosphite, without Brønsted-acid sites, should possess a relatively low activity in acid-catalysed reactions. However, Cheng and Clearfield ${ }^{9}$ found that zirconium phosphite gave high conversions in alcohol dehydration reactions. Under their reaction conditions, only ethanol conversions above $80 \%$ were obtained and ethene was the main product. Nevertheless, the active sites for alcohol dehydration over zirconium phosphite were unclear. Since the catalyst was calcined at $673 \mathrm{~K}$ in air overnight, the question arises as to whether the dehydration activity of this catalyst is due to the very weak acidity of phosphite groups or the Brønsted acidity resulting from the oxidation of phosphite groups to phosphate.

In the present work, the catalytic behaviour of zirconium phosphite, uncalcined and calcined at $673 \mathrm{~K}$, was evaluated by using the dehydration of ethanol. The structural changes due to calcination were carefully examined. The results were compared with that of zirconium phosphate in order to elucidate the active sites. Kinetic data were obtained and analysed, and mechanisms for ethanol dehydration were proposed for these compounds.

\section{Experimental}

Three crystalline samples were used as catalysts. They were $\alpha$-zirconium phosphate $\left[\left(\alpha-\mathrm{Zr}\left(\mathrm{HPO}_{4}\right)_{2}(2.5: 48)\right]\right.$ and zirconium phosphite $\left[\mathrm{Zr}\left(\mathrm{HPO}_{3}\right)_{2}(2.5: 48)\right]$ calcined in air at 673 $\mathrm{K}$ overnight and a zirconium phosphite sample without calcination. The term $(2.5: 48)$ designates that the samples are prepared by refluxing $\mathrm{Zr}\left(\mathrm{HPO}_{3}\right)_{2}$ gel in $2.5 \mathrm{~mol} \mathrm{dm}{ }^{-3}$ phosphorous acid [or phosphoric acid for $\alpha-\mathrm{Zr}\left(\mathrm{HPO}_{4}\right)_{2}$ ] for a period of $48 \mathrm{~h}$

X-Ray powder diffraction patterns of the catalysts were taken using a Phillips PW1729 diffractometer with $\mathrm{Cu}-\mathrm{K} x$ radiation. B.E.T. surface areas of the catalysts were measured with a Micromeritics Accusorb 2100E unit. Thermogravimetric analysis (TG) was carried out with a Du Pont 9900 thermal analysis system in air in order to simulate catalyst pretreatment conditions. The system was first heated to 373 $\mathbf{K}$ and maintained for $30 \mathrm{~min}$ to expel physically adsorbed moisture. Then the temperature was raised to $673 \mathrm{~K}$ with a heating rate of $10 \mathrm{~K} \mathrm{~min}^{-1}$, and the final temperature was maintained for $8 \mathrm{~h}$.

IR spectra were obtained with a Bomen DA 3.02 FT-IR spectrometer. The self-suppporting catalyst wafer used for examining the stretching modes of surface hydroxyl groups was of surface density $0.01 \mathrm{~g} \mathrm{~cm}^{-2}$.

Ethanol dehydration was conducted in an ordinary flowtype reactor under atmospheric pressure. All catalysts except the uncalcined zirconium phosphite sample were calcined at $673 \mathrm{~K}$ in air overnight prior to the reaction. The uncalcined sample was evacuated at room temperature under a reduced pressure of $10^{-2}$ Torr $\dagger$ overnight prior to the reaction. The ethanol dehydration was carried out by passing the ethanol vapour through the catalyst bed with a helium carrier. The products were analysed by an on-line Hewlett Packard 5830A gas chromatograph with a TCD detector. A Porapak $\mathrm{N}$ column was used for the separation. The conversion, selec-

+1 Torr $=133322 \mathrm{~Pa}$ 
tivity and yield were calculated on the basis of carbon atoms and were defined as the following:

Conversion $=$ moles of ethanol consumed $/$ moles of ethanol fed

Selectivity for a given hydrocarbon,

$=($ moles of hydrocarbon $\times$ no. of $\mathrm{C}$ atoms in the Yield molecular formula $) /($ moles of ethanol consumed $\times 2$ )

$=($ moles of hydrocarbon $\times$ no. of $\mathrm{C}$ atoms in the molecular formula $) /($ moles of ethanol fed $\times 2$ )

\section{Results and Discussion}

The B.E.T. surface areas of the catalysts are tabulated in Table 1. Both calcined and uncalcined samples of zirconium phosphite have similar surface areas. Thus, calcination does not change the surface area of zirconium phosphite. The bulk structural change of zirconium phosphite before and after calcination was examined with X-ray powder diffractometry and IR spectroscopy. The XRD pattern of the calcined sample remained the same as that of the uncalcined one, and maintained the $5.58 \AA$ interlayer spacing. The IR absorbance spectra of the uncalcined and calcined samples of zirconium phosphite are shown in Fig. 1(a) and 1(b), respectively, and they demonstrate that there are no detectable changes in the structure. The split band of strong intensity around 1050 $\mathrm{cm}^{-1}$ corresponds to the $\mathrm{P}-\mathrm{O}$ stretching vibration. The sharp peak of medium intensity at $c a .2470 \mathrm{~cm}^{-1}$ corresponds to the $\mathrm{P}-\mathrm{H}$ stretching vibration. However, only extremely weak peaks were detected in the $\mathrm{O}-\mathrm{H}$ stretching region around $3500 \mathrm{~cm}^{-1}$ for both samples. These peaks are probably due to the moisture adsorbed on the $\mathrm{KBr}$ pellets.

The oxidation behaviour of zirconium phosphite in air was examined by thermogravimetric analysis. Fig. 2 shows

Table 1 B.E.T. Surface areas of catalysts

\begin{tabular}{lc}
\multicolumn{1}{c}{ catalysts } & $\begin{array}{c}\text { B.E.T. surface } \\
\text { area } / \mathrm{m}^{2} \mathrm{~g}^{-1}\end{array}$ \\
\hline$\alpha-\mathrm{Zr}\left(\mathrm{HPO}_{4}\right)_{2}(2.5: 48)$ & 33 \\
$\mathrm{Zr}\left(\mathrm{HPO}_{3}\right)_{2}(2.5: 48)$, uncalcined & 66 \\
$\mathrm{Zr}\left(\mathrm{HPO}_{3}\right)_{2}(2.5: 48)$, calcined & 63 \\
\hline
\end{tabular}

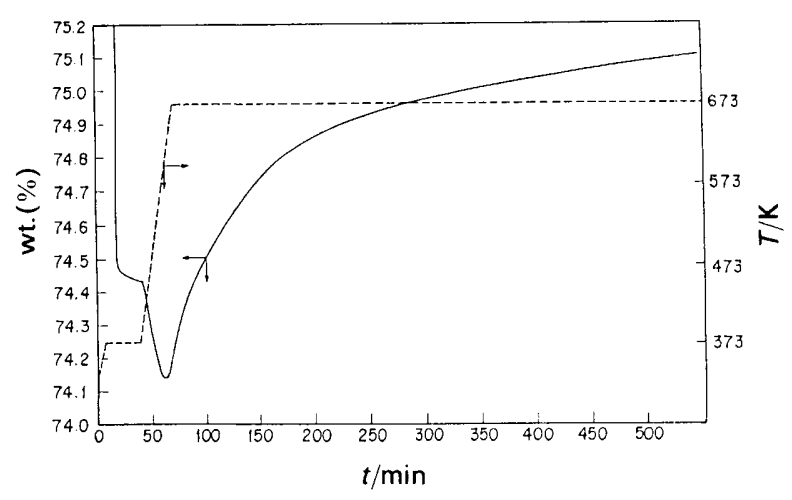

Fig. 2 Weight change of zirconium phosphite as a function of heat treatment in air. (-) weight loss; $(--)$ temperature profile

weight-loss data for the zirconium phosphite sample and the temperature profile as a function of run time. The results indicate that a significant amount of physically adsorbed moisture is released from the zirconium phosphite below $373 \mathrm{~K}$, and the catalyst begins to gain weight at $602 \mathrm{~K}$. After heating the sample for $8 \mathrm{~h}$ at $673 \mathrm{~K}$, the weight gain is $0.97 \%$ based on the initial weight of the catalyst. This weight gain of zirconium phosphite is associated with the process of oxidation of phosphite to phosphate. Since the bulk structure of the calcined sample is unchanged, the oxidation should occur on the exterior surface layer. According to the known unitcell dimension of $\alpha$-zirconium phosphate, each phosphate group occupies $c a$. $24 \AA^{2}$. ${ }^{3}$ The same value is expected for the phosphite groups on zirconium phosphite. If only the exterior surface of zirconium phosphite was completely oxidized, the sample with a surface area of $66 \mathrm{~m}^{2} \mathrm{~g}^{-1}$ should increase by $0.73 \%$ of the catalyst weight due to oxygen uptake. This value is close to the actual weight gain of $0.97 \%$ indicating that all phosphite groups on the exterior surface of zirconium phosphite may have been oxidised to phosphate groups after heating in air at $673 \mathrm{~K}$ for $8 \mathrm{~h}$.

Changes in the surface structure were clearly demonstrated in the diffuse-reflectance IR Fourier-transform (DRIFT) spectra, (Fig. 3). The uncalcined zirconium phosphite sample shows an extra peak at $2458 \mathrm{~cm}^{-1}$ in the $\mathrm{P}-\mathrm{H}$ stretching

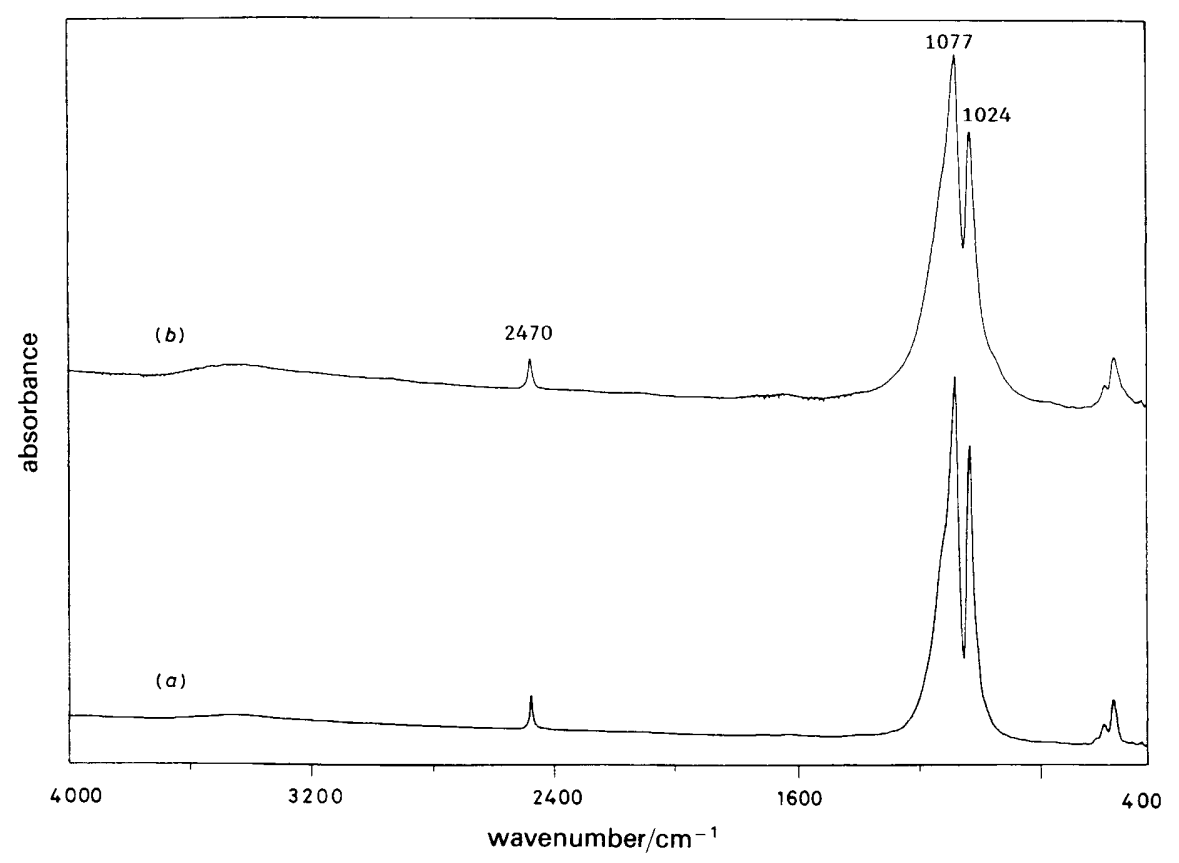

Fig. 1 IR absorbance spectra of $\mathrm{Zr}\left(\mathrm{HPO}_{3}\right)_{2}(2.5: 48)(a)$ before and $(b)$ after calcination at $673 \mathrm{~K}$ in air 


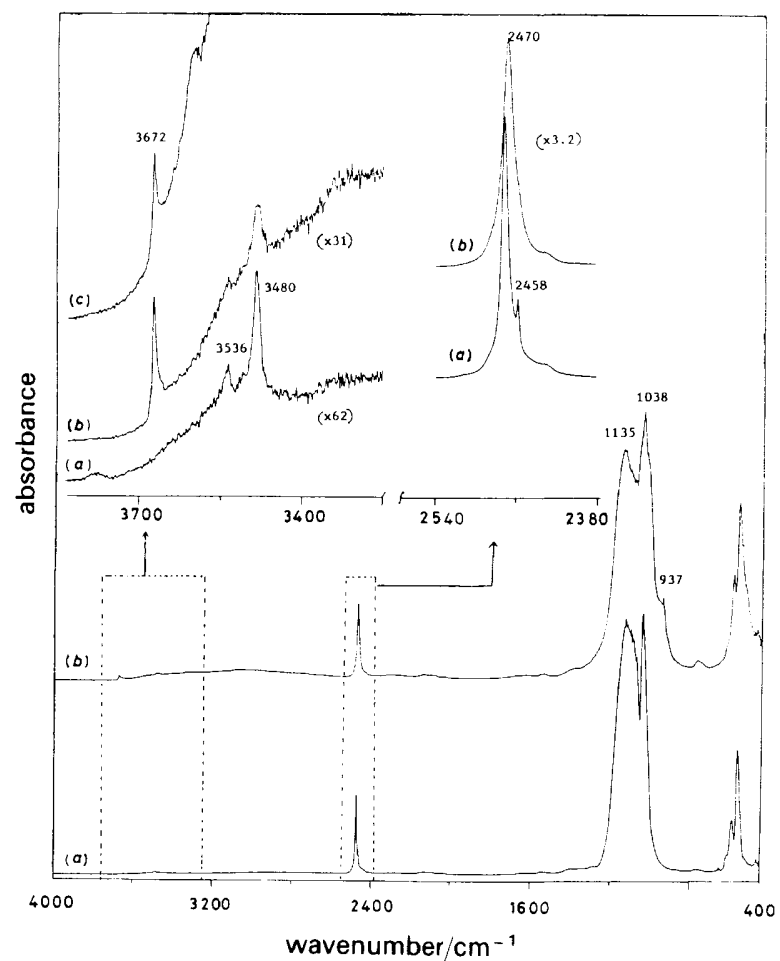

Fig. 3 DRIFT spectra (with a portion enlarged) of $(a)$ uncalcined zirconium phosphite, $(b)$ calcined zirconium phosphite and (c) calcined zirconium phosphate

region in addition to the peak at $2471 \mathrm{~cm}^{-1}$, the latter also being observed on the absorbance spectrum. The former peak, however, was found to disappear after the sample was calcined at $673 \mathrm{~K}$, concomitant with two new peaks appearing at $3672 \mathrm{~cm}^{-1}$ in the $\mathrm{O}-\mathrm{H}$ stretching region and at 937 $\mathrm{cm}^{-1}$ in the $\mathrm{P}-\mathrm{O}$ stretching region. The $3672 \mathrm{~cm}^{-1}$ peak was also observed on the calcined zirconium phosphate. It was attributed to the $\mathrm{O}-\mathrm{H}$ stretch of isolated $\mathrm{P}-\mathrm{OH}$ groups, ${ }^{10}$ and was also observed on aluminum phosphate and boron phosphate. ${ }^{11}$ As a result, the $2458 \mathrm{~cm}^{-1}$ peak is assigned to the $\mathrm{P}-\mathrm{H}$ groups on the surface of the zirconium phosphite. This peak disappears when surface $\mathrm{P}-\mathrm{H}$ groups are transformed to $\mathrm{P}-\mathrm{OH}$ after zirconium phosphite is calcined at $673 \mathrm{~K}$.

In order to clarify the active sites on the surface of zirconium phosphite, a self-supporting zirconium phosphite wafer was used for IR absorbance spectra in situ. Two peaks of weak intensity similar to those in the DRIFT spectra, were observed at 3480 and $3536 \mathrm{~cm}^{-1}$ in the $\mathrm{O}-\mathrm{H}$ stretching region in the uncalcined sample, the latter being degassed under a reduced pressure of $10^{-5}$ Torr at $373 \mathrm{~K}$ [Fig. 4(a)]. After the sample was calcined in air at $673 \mathrm{~K}$ for $4 \mathrm{~h}$, the 3672 $\mathrm{cm}^{-1}$ peak appeared [Fig. 4(b)], and the surface of the calcined sample became very hydrophilic. Many peaks attributed to adsorbed moisture were observed, even though the wafer was degassed at $400 \mathrm{~K}$ for $1 \mathrm{~h}$, and eventually disappeared after degassing at $673 \mathrm{~K}$ [Fig. 4(c)]. However, the $3672 \mathrm{~cm}^{-1}$ peak was much more intense than the two peaks at 3480 and $3536 \mathrm{~cm}^{-1}$. When ethanol vapour was introduced into the IR cell, the intensity of the $3672 \mathrm{~cm}^{-1}$ peak was found to decrease significantly while the peaks at 3480 and $3536 \mathrm{~cm}^{-1}$ remained unaffected [Fig. $4(d)$ ]. The intensity of the $3672 \mathrm{~cm}^{-1}$ peak was regained after the IR cell was degassed at $473 \mathrm{~K}$ and the adsorbed ethanol molecules were removed [Fig. $4(e)]$. The appearance of the $3672 \mathrm{~cm}^{-1}$ peak is evidence that the $\mathrm{P}-\mathrm{H}$ groups on the surface of the zirconium phosphite were oxidized to the $\mathrm{P}-\mathrm{OH}$ groups

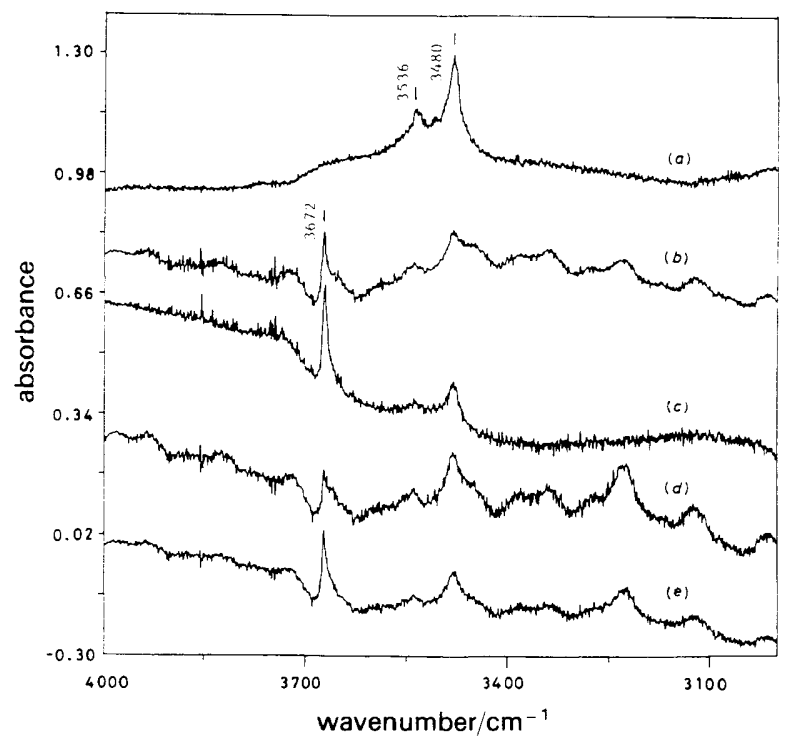

Fig. 4 IR spectra of zirconium phosphite wafer in the $\mathrm{O}-\mathrm{H}$ stretching region. (a) Uncalcined sample degassed at $373 \mathrm{~K}, 50 \mathrm{~min}$, (b) calcined sample degassed at $400 \mathrm{~K}(1 \mathrm{~h}),(c)$ calcined sample degassed at $673 \mathrm{~K},(d)$ introduction of 20 Torr ethanol vapour onto calcined sample and degassed for $10 \mathrm{~min},(e)$ degassed sample, $(d)$ at $473 \mathrm{~K}, 10 \mathrm{~min}$

during the calcination process. Moreover, these $\mathrm{P}-\mathrm{OH}$ groups interacted with adsorbed ethanol and were proposed as being the acid sites on the calcined zirconium phosphite for ethanol dehydration. However, the peaks at 3480 and $3536 \mathrm{~cm}^{-1}$, which were observed on both zirconium phosphite samples before and after calcination, were not active towards ethanol dehydration. These $\mathrm{O}-\mathrm{H}$ groups were more likely to be formed as lattice defects and hidden in the interior of the layered zirconium phosphite.

The rates of catalytic dehydration of ethanol were calculated on the basis of the differential reactor model. Thus, only the data for 3-20\% total conversion were used for the calculation. Table 2 shows that the catalytic activities of the surfaces of $\mathrm{Zr}\left(\mathrm{HPO}_{4}\right)_{2}(2.5: 48)$ and calcined $\mathrm{Zr}\left(\mathrm{HPO}_{3}\right)_{2}(2.5: 48)$ are similar since their reaction rates are similar for production of diethyl ether and ethene. However, uncalcined $\mathrm{Zr}\left(\mathrm{HPO}_{3}\right)_{2}(2.5: 48)$ shows a greater propensity for ether formation. The rate of production of diethyl ether over this catalyst is approximately one order of magnitude higher than that of ethene.

Table 3 shows the apparent activation energies for ethanol dehydration over these catalysts. The value for ethene formation is $10 \mathrm{kcal} \mathrm{mol}^{-1}$ larger than that for diethyl ether over uncalcined zirconium phosphite. This large energy barrier explains the low production rate of ethene. However, the apparent activation energies for ethene and diethyl ether formation over $\mathrm{Zr}\left(\mathrm{HPO}_{4}\right)_{2}(2.5: 48)$ and calcined $\mathrm{Zr}\left(\mathrm{HPO}_{3}\right)_{2}(2.5: 48)$ samples are within a close range around $26 \mathrm{kcal} \mathrm{mol}^{-1}$. These results imply that the active sites on

Table 2 Product production rates of ethanol dehydration at $540 \mathrm{~K}$

\begin{tabular}{lcc}
\hline \multicolumn{1}{c}{ catalysts } & $\begin{array}{c}\text { production } \\
\text { rate of } \\
\text { ethene } \\
/ 10^{-8} \mathrm{~mol} \\
\mathrm{~min}^{-1} \mathrm{~m}^{-2}\end{array}$ & $\begin{array}{c}\text { production } \\
\text { rate of } \\
\text { diethyl ether } \\
/ 10^{-8} \mathrm{~mol} \\
\mathrm{~min}^{-1} \mathrm{~m}^{-2}\end{array}$ \\
\hline$\alpha-\mathrm{Zr}\left(\mathrm{HPO}_{4}\right)_{2}(2.5: 48)$ & 6.2 & 3.1 \\
$\mathrm{Zr}\left(\mathrm{HPO}_{3}\right)_{2}(2.5: 48)$, uncalcined & 1.8 & 12.0 \\
$\mathrm{Zr}\left(\mathrm{HPO}_{3}\right)_{2}(2.5: 48)$, calcined & 5.4 & 4.9 \\
\hline
\end{tabular}


Table 3 Apparent activation energy for ethanol dehydration

\begin{tabular}{lcc}
\hline \multicolumn{1}{c}{ catalysts } & \multicolumn{2}{c}{$\begin{array}{c}\text { apparent activation } \\
\text { energies } / \mathrm{kcal} \mathrm{mol}^{-1}\end{array}$} \\
\cline { 2 - 3 } & ethene & diethyl ether \\
\hline$\alpha-\mathrm{Zr}\left(\mathrm{HPO}_{4}\right)_{2}(2.5: 48)$ & 27 & 27 \\
$\mathrm{Zr}\left(\mathrm{HPO}_{3}\right)_{2}(2.5: 48)$, uncalcined & 36 & 26 \\
$\mathrm{Zr}\left(\mathrm{HPO}_{3}\right)_{2}(2.5: 48)$, calcined & 26 & 25 \\
\hline
\end{tabular}

Reaction temperature $=540-610 \mathrm{~K}$.

these two catalysts are similar. The Brønsted acidity of the orthophosphate groups is proposed as being the common active site.

The selectivities and yields of diethyl ether in ethanol dehydration are plotted against ethanol conversion values in Fig. 5-7. Since ethene and diethyl ether were the only two products, the selectivity of ethene was obtained by subtracting the selectivity of ether from unity, and the yield of ethene was obtained by substracting the yield of ether from the total ethanol converted. It was found that the selectivities of ether over the $\alpha$-zirconium phosphate and the calcined zirconium phosphite were independent of the reaction temperature because similar activation energies were obtained for ether and ethene formation. In contrast, the selectivity of ether

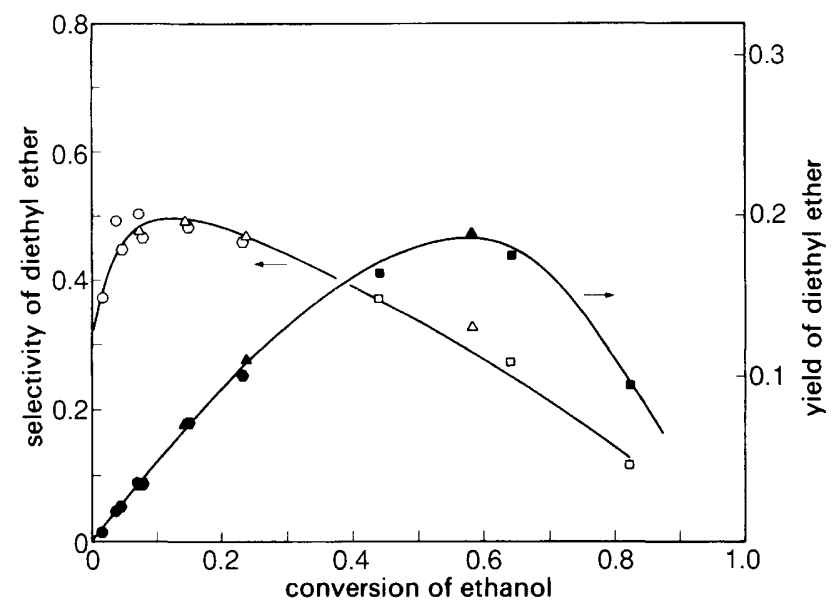

Fig. 5 Selectivity and yield of ether in ethanol dehydration over $\alpha$-zirconium phosphate $\bigcirc, 540 \mathrm{~K} ; \triangle, 567 \mathrm{~K} ; \bigcirc, 607 \mathrm{~K} ; \square, 616 \mathrm{~K}$

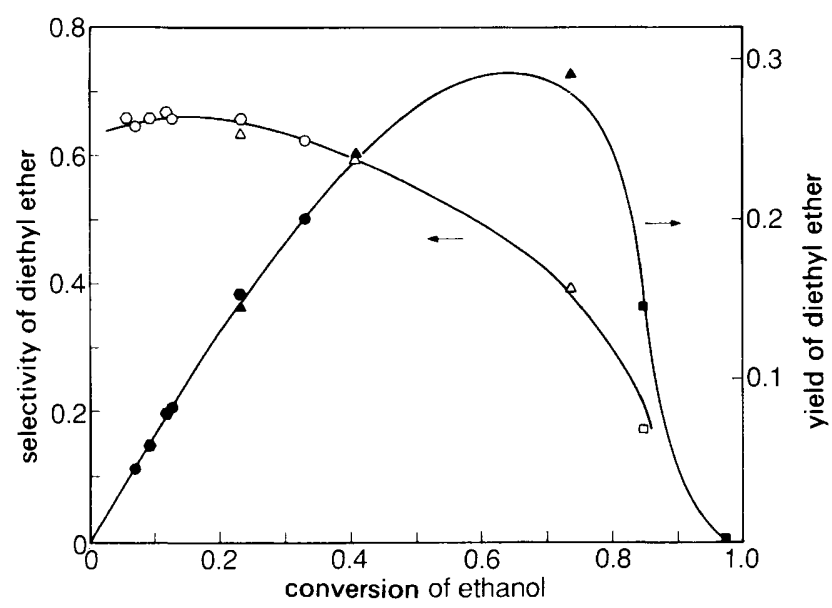

Fig. 6 Selectivity and yield of ether in ethanol dehydration over calcined zirconium phosphite (673 $\mathrm{K}$ in air overnight) $0,540 \mathrm{~K} ; \triangle$, $570 \mathrm{~K} ; \bigcirc, 610 \mathrm{~K} ; \square, 620 \mathrm{~K}$

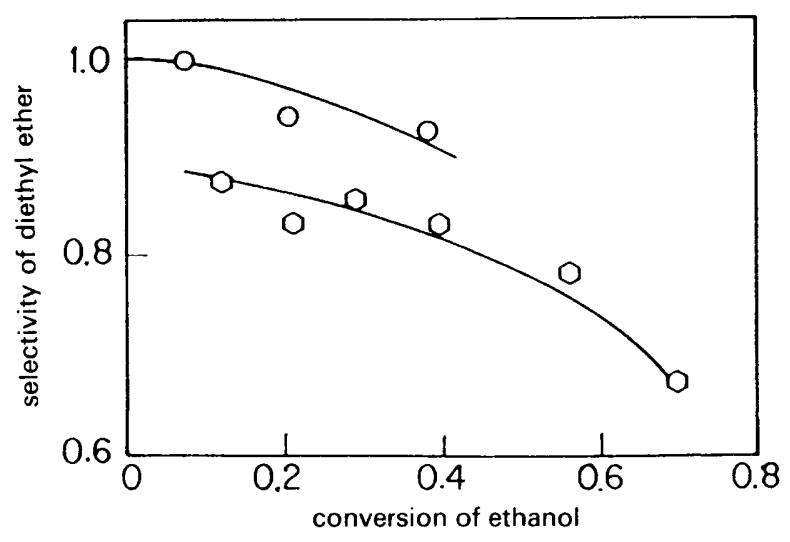

Fig. 7 Selectivity of ether in ethanol dehydration over uncalcined zirconium phosphite $\bigcirc, 540 \mathrm{~K} ; 0,600 \mathrm{~K}$

decreases with reaction temperature over the uncalcined zirconium phosphite sample due to the higher activation energy for ethene formation.

Three pathways have been proposed in the literature in the formation of ethers and alkenes from alcohol dehydration. ${ }^{12}$ These are: (i) consecutive, (ii) parallel and (iii) a combination of consecutive and parallel reactions. The reaction sequences over our catalysts can be further elucidated from Fig. 5-7. When ethanol conversion is low, the formation of ether and ethene takes place in parallel reaction paths over $\alpha$-zirconium phosphate and calcined zirconium phosphite because at zero conversion the intercepts of ether selectivity curves are neither unity nor zero. ${ }^{13}$ Nevertheless, the yields of diethyl ether decrease with increasing conversion when the conversion $>0.6$, indicating that consecutive transformation of ether to ethene also occurs over these two catalysts. Therefore, 'combination' pathways were observed over $\alpha$ zirconium phosphate and calcined zirconium phosphite.

An unusual phenomenon was found over $\alpha$-zirconium phosphate and calcined zirconium phosphite when the conversion of ethanol was $<0.1$. The selectivities of ether increase with the increase in total conversion. Thus, ethene is likely to be transformed to diethyl ether through combination with ethanol, the latter being abundant during this part of the conversion. This reverse reaction of ethene is more apparent over $\alpha$-zirconium phosphate than over calcined zirconium phosphite. This is attributed to the stronger polar interaction between the ethanol and phosphate groups on the former compound. Consequently, the reaction sequence of ethanol dehydration over $\alpha$-zirconium phosphate and calcined zirconium phosphite can be summarized in the following scheme:

$$
\begin{gathered}
\mathrm{C}_{2} \mathrm{H}_{5} \mathrm{OH}-\mathrm{C}_{2} \mathrm{H}_{5} \mathrm{OC}_{2} \mathrm{H}_{5}+\mathrm{H}_{2} \mathrm{O} \\
-\mathrm{C}_{2} \mathrm{H}_{5} \mathrm{OH} \downarrow \uparrow+\mathrm{C}_{2} \mathrm{H}_{5} \mathrm{OH} \\
\mathrm{C}_{2} \mathrm{H}_{4}+\mathrm{H}_{2} \mathrm{O}
\end{gathered}
$$

In the comparison of Fig. 5 and 6, it was found that the selectivity and yield of ether over calcined zirconium phosphite were always higher than over zirconium phosphate. This is attributed to the Brønsted acidity of the surface phosphate groups on calcined zirconium phosphite not being as strong as that on zirconium phosphate, because the interior of zirconium phosphite particles retains the phosphite groups, and the number of oxygen atoms contributing to the electron-withdrawing effect is smaller in the latter compound.

The catalytic behaviour of uncalcined zirconium phosphite was completely different from that observed for the calcined sample and for zirconium phosphate. Fig. 7 shows that the intercept of ether selectivity is unity at zero conversion when 
the reaction temperature is $540 \mathrm{~K}$. This implies that ether is the only product when the conversion is low and that ethene is formed via a consecutive pathway. ${ }^{13}$ At $610 \mathrm{~K}$, however, the intercept of the ether curve is $c a$. 0.9 , implying that a parallel pathway occurs at the higher temperature. Nevertheless, the phenomenon of converting ethene to ether at low ethanol conversion was not observed over this uncalcined compound. Since zirconium phosphite, in this case, could not be oxidized during the pretreatment or reaction stages, the catalytic performance at different temperatures is attributed to the enhancement of the acidity as the temperature is raised.

The mechanism for ethanol dehydration to ethene over zirconium phosphate as proposed by Cheng et al. ${ }^{5}$ involves an intermediate step involving a $\beta$-elimination from a sixmembered ring to form ethene. Since similar activation energies were obtained in this study for the formation of ethene and diethyl ether over the catalysts containing phosphate groups on the surface, the formation of ethoxy species is proposed as being common to both reactions. The mechanism proposed is as follows.

1. The formation of ethoxy groups on the surface accompanied by the condensation of water at the Brønsted-acid sites of zirconium phosphate.

$$
\mathrm{CH}_{3} \mathrm{CH}_{2} \mathrm{OH}+\geqslant \mathrm{P}-\mathrm{OH} \longrightarrow \geqslant \mathrm{P}-\mathrm{OCH}_{2} \mathrm{CH}_{3}+\mathrm{H}_{2} \mathrm{O}
$$

2. Ethene formation via a four-membered ring intermediate.

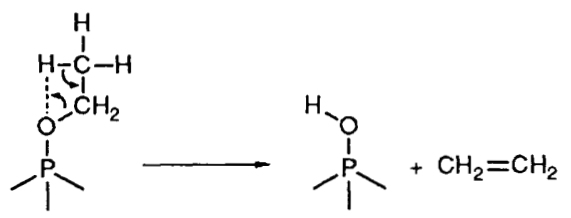

3. In parallel with step 2 , formation of diethyl ether may take place via a four-membered ring intermediate.

$$
\text { CH }
$$

Ethene formation is favourable because of the cage effect of the ethoxy group. However, the electron-transfer process is facilitated by the relatively acidic protons on the incoming ethanol molecules in the ether formation. As a result, similar activation energies were obtained for these two reactions.

Regarding the dehydration reactions on uncalcined zirconium phosphite, it is proposed that ethanol adsorbs on the surface through polarized bonding. Although the Pauling electronegativities of phosphorus and hydrogen are similar, the phosphite group exhibits a partial positive charge on the hydrogen as a result of the electron-withdrawing effect from the oxygen atoms around the phosphorus atoms. Again, four-membered ring intermediates are proposed for the formation of ether and ethene. However, ethene is produced in addition to diethyl ether at low temperatures.

1. Chemisorption of ethanol.

$$
\mathrm{CH}_{3} \mathrm{CH}_{2} \mathrm{OH}+\gtreqless \mathrm{P}-\mathrm{H} \longrightarrow \stackrel{\delta-}{\mathrm{P}}-\mathrm{H} \cdots \mathrm{O}^{-} \stackrel{\mathrm{O}_{+}^{+}}{\mathrm{CH}_{2} \mathrm{CH}_{3}}
$$

2. Diethyl ether formation via a four-membered ring intermediate.

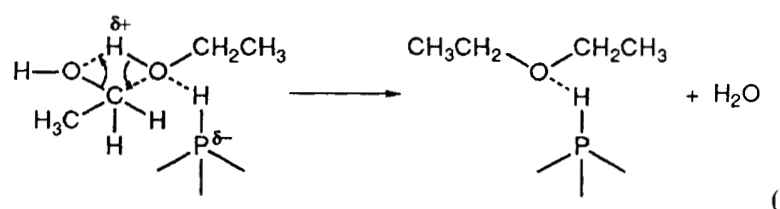

3. Ethene formation from surface-adsorbed diethyl ether via a four-membered ring intermediate.<smiles>CCCOC([PH](C)(C)C)P(C)(C)(C)C</smiles>

\section{Conclusions}

The following conclusions may be drawn from this study:

1. The calcination of zirconium phosphite in air at $673 \mathrm{~K}$ generates Brønsted-acid sites on the exterior surface by the oxidation of phosphite groups to phosphate, although the bulk structure is not changed.

2. The IR spectrum of calcined zirconium phosphite shows a new peak appearing at $3672 \mathrm{~cm}^{-1}$ in the $\mathrm{O}-\mathrm{H}$ stretching vibration region. This intensity of this peak decreases with the introduction of ethanol and the peak is attributed to free $\mathrm{P}-\mathrm{OH}$ groups on the surface. The other two peaks at 3480 and $3636 \mathrm{~cm}^{-1}$, which are attributed to $\mathrm{O}-\mathrm{H}$ groups in lattice defects, were insensitive to the presence of ethanol.

3. The ethanol dehydration catalysed by the Brønsted acidity of phosphate groups yields ethene and diethyl ether via a parallel pathway when the ethanol conversion is low, but also via a consecutive pathway when the conversion is high. Furthermore, ethene appeared to combine with ethanol and be converted into ether when the ethanol conversion was lower than $10 \%$.

4. The uncalcined zirconium phosphite sample demonstrates weaker acidity than the calcined one. Ether formation is preferred to ethene over the former catalyst. After examining the selectivity as a function of conversion, it is proposed that ethene is formed via adsorbed diethyl ether.

5 . The acidity of uncalcined zirconium phosphite is presumed to be due to the polar $\mathrm{P}-\mathrm{H}$ bonds and the highly electronegative oxygen atoms around the phosphorus atom.

\section{References}

1 M. B. Dines and P. M. Digiacomo, Inorg. Chem., 1981, 20, 92.

2 C. Alberti, U. Costantino, S. Allulli and N. Tomassini, Inorg. Nucl. Chem., 1978, 40, 1113.

3 A. Clearfield and G. D. Smith, Inorg. Chem., 1969, 8, 431.

4 A. Clearfield and D. S. Thakur, J. Catal., 1980, 54, 185.

5 S. Cheng, G. Z. Peng and A. Clearfield, IEC Prod. Res. Dev., $1984,23,219$

6 K. I. Segawa, J. Catal., 1985, 94, 491.

7 M. B. Dines, P. D. Di. Giacomo, K. P. Callahan, P. C. Griffith, R. H. Lane and R. E. Cooksey, in ACS Symp. Ser. 192, American Chemical Society, Washington, D.C., 1982, ch. 13.

8 B.-Z. Wan, R. G. Anthony, G. Z. Peng and A. Clearfield, J. Catal., 1986, 101, 19

9 S. Cheng and A. Clearfield, Appl. Catal., 1986, 26, 91.

10 D. S. Thakur, S. Cheng and A. Clearfield, unpublished work.

11 J. B. Peri, Discuss. Faraday Soc., 1971, 52, 55.

12 P. L. Yue and O. Olaofe, Chem. Eng. Res. Des., 1984, 62, 81.

13 G. C. Bond in Heterogeneous Catalysis-Principles and Applications, ed. G. C. Bond, Oxford, University Press, New York, 2nd edition, 1987, p. 53. 